\title{
Status of Child Health in Megacities of India
}

\author{
Anandita Dawn', Ranjan Basu ${ }^{2}$ \\ ${ }^{1}$ Research Fellow, Department of Geography, University of Calcutta, Kolkata, West Bengal, India \\ ${ }^{2}$ Professor, Department of Geography, University of Calcutta, Kolkata, West Bengal, India
}

\begin{abstract}
The Census of India, 2011 identifies eight megacities in India located in the major States of Tamil Nadu, Karnataka, Andhra Pradesh, West Bengal, Gujarat and Maharashtra and the National Capital Region of Delhi. These megacities exert a profound influence on the socio-economic life of not only the concerned State but of the surrounding territories also. They are generally marked with administrative coherence, sound planning for development accompanied with boastful infrastructural facilities and urban amenities. Despite such glorious and attractive life, these cities have a darker social side as well. They suffer from the problem of migration of the poor people leading to the growth of registered slums and unauthorized shanties. The uncontrolled growth of population thus culminates into a number of social and economic problems inclusive of poverty, unemployment, social deprivation and social pathological issues. This research endeavor therefore tries to focus on the demographic problems related to sex ratio (both general and child) and status of education particularly that of the female counterparts. It further attempts to throw light on the existing situation of child health dealing with the evils of under-age marriage of girls, domiciliary deliveries inclusive of its consequences along with child death below one year and below five years of age.
\end{abstract}

Keywords: poverty, urban magnet, sex ratio, child death, domiciliary deliveries

\section{Introduction}

Available infrastructures along with history, culture and political ideologies of different countries have shaped their strategies towards universalization of health care. India being one of the developing economies in the world is perhaps the most unique of its kind with well-marked diversities in every sphere of its existence. The country is a federal union of States comprising of 29 States and seven Union Territories. Out of the 29 States, 17 are considered as the major States with a population size of more than 20 million [Government of India, 2012]. The number of megacities in the country in 2001 was six which has increased to eight in 2011. Urbanization and migration go hand in hand and together they change the population geography of any region [Whaba, 1996]. The population growth in the megacities is high owing to the operation of the 'pull' factors of migration inclusive of better employment opportunities, health care and educational facilities and scope of higher standard of living. The uncontrolled inflow of immigrants has thus created tremendous pressure on the socio-economic infrastructure which has adversely affected the development process in the megacities. The unwanted growth of registered slums and unauthorized shanties in the nook and corner of the megacities has ultimately led to a situation where the social set-up has suffered the most especially that of the condition of maternal and child health.

\section{Objectives of Study}

The study has been initiated to fulfill the following objectives:

- To understand the demographic peculiarities as well as the underlying problems related to population growth in the megacities

- To study the social infrastructure including the condition of health and education in these areas

- To throw light on the situation of child health below six years of age in these super-urban areas
- To investigate on the status of girl children below six years of age in the slums and shanties of the megacities

- To find out the Government initiatives undertaken to improve the situation of child health on one hand and of the health care facilities on the other

\section{Area under Study}

This research endeavor covers the eight megacities of India viz. Mumbai and Pune, Kolkata, Chennai, Hyderabad, Bengaluru, Ahmedabad located in six major States of Maharashtra, West Bengal, Tamil Nadu, Andhra Pradesh, Karnataka and Gujarat as well as one Union Territory of Delhi which is designated as the 'National Capital Region' (NCR) [Census of India, 2011]. Among these six major States, three are the southern major States of Tamil Nadu (Chennai), Karnataka (Bengaluru) and Andhra Pradesh (Hyderabad), two are the western major States of Maharashtra (Mumbai and Pune) and Gujarat (Ahmedabad) and one is the eastern major State of West Bengal (Kolkata). The number of megacities was six in 2001 including Delhi, Kolkata, Chennai, Mumbai, Bengaluru and Hyderabad. Two more million-plus cities of Ahmedabad and Pune received the status of megacity in 2011.

\section{Materials and Methods}

This research article is based mainly on the analysis of secondary data derived from various Government sources inclusive of the Census of India under the Directorate of Census Operations and Registrar General of India as well as the District Level Household and Facility Survey (DLHFS) conducted by the Ministry of Health and Family Welfare, apart from, some crucial collections from the International Institute of Population Sciences, Mumbai. Despite acquiring data and other relevant information from reliable Government sources, major part of the information does not cover the maternal and child health condition in the megacity of Ahmedabad. The articles published in the popular 'International Journal of Community Medicine' 


\section{International Journal of Science and Research (IJSR) \\ ISSN (Online): 2319-7064 \\ Index Copernicus Value (2013): 6.14 | Impact Factor (2015): 6.391}

have been consulted for the purpose. A number of newspaper reports published in the Times of India have also been considered to ascertain the recent status of the health condition in the megacities. Besides data, a number of books have been consulted which has added to the literature of the topic providing it a sound base for study.

The secondary data collected from various Government sources have been classified and tabulated to facilitate the process of representation. The computation and depiction of the data has been accomplished through cartographic techniques using the Microsoft Excel software. The final shape of the work has been given based on the representation and analysis of the data collected followed by their suitable interpretation.

\section{Demographic Growth and Trend in the Megacities}

The demographic trend of the megacities is distinct and unique from one another. The megacity of Mumbai (erstwhile Bombay) is the capital city of the western major Indian State of Maharashtra. In 2009, Mumbai was included in the list of Global Cities and also known as the 'World City' (the term was first initiated by Patrick Geddes in 1915) or 'Alpha World City'. The residents of Mumbai are usually called Mumbaikar, Mumbaiite, Bombayite or Bombaiite. The population density is estimated to be about 20,482 persons / $\mathrm{km}^{2}$ [Census of India, 2011]. The decadal population growth rate in the city has declined to 4.7 per cent in 2011. The city has the largest percentage of slum population among the other megacities in the country. The percentage of slum population to total urban population in 2011 in the municipal corporation under Mumbai megacity was 41.84 .

The Delhi megacity has registered tremendously high population growth in 1951 (90\%) owing to large-scale immigration following partition of India in 1947. The population growth rate has, however, stabilized since 1961. As per the latest census of 2011, the population growth rate of the city is 21.6 per cent.

The percentage growth of population in case of Bengaluru, the capital city of the southern major State of Karnataka is 12.09 which is mainly due to the fact that this city has proved itself to be the most lucrative one and is aptly called the 'Silicon Valley of India' because of its role as the nation's leading information technology (IT) exporter.

The Megacity of Hyderabad is the joint capital of two southern States of Andhra Pradesh, a major State and the newborn State of Telengana (formed on $2^{\text {nd }}$ June, 2014). A tremendous hike in population size has been registered since 1971 with the infrastructural development in the State. It is housing many educational and research institutions.

The decadal population growth rate of Ahmedabad, the capital city of the western major State of Gujarat recorded a drop by 3.22 per cent during the decade of 2001-2011. Ahmedabad is the land of the rich Gujarati merchants and businessmen. There is also a sizeable proportion of population comprising of Punjabis, Marathis, Tamils,
Sindhis, Malayalis and Marwaris who brought their native language and culture to the city.

The population growth has been positive in Chennai (erstwhile Madras), the capital city of the southern major State of Tamil Nadu by a percentage of 6.09. As per the Religious Census of 2011 conducted by the Government of India, Chennai had 80.73 per cent Hindus, 9.45 per cent Muslims, 7.72 per cent Christians, 0.06 per cent Sikhs, 0.06 per cent Buddhists, 1.11 per cent Jains and 0.83 per cent other religious communities.

The population density of Kolkata $(24,306$ number of persons $/ \mathrm{km}^{2}$ in 2011) is abnormally high in comparison to other districts within the State of West Bengal. The decadal change of population in the city was negative i.e. -1.88 per cent in the last decade of 2001-2011 [Census of India, 2011].

\section{Results and Discussion}

This research endeavor covering the eight megacities of India has thrown spotlight on a number of facets relating to child health. These aspects related to health of the children below six years of age have been discussed under the following broad heads and sub-heads.

\subsection{Attributes Related to Child Health in the Megacities}

The status of child health depends on a number of factors including condition of maternal health during pre-partum and post-partum period coupled with nature of childhood care especially that of the girl children below six years of age. The various attributes which exert a profound influence on the situation of child health in the megacities of India inclusive of growth of child population in the 0-6 years age group have been discussed underneath.

\subsection{Growth of Child Population}

The megacities of India are characterized by declining crude birth and death rate coupled with decreasing percentage of child population in the age group of 0-6 years. The population growth in these megacities is mainly increasing due to inter-urban migration in search of employment, education and a descent standard of living. These megacities represent perfect examples of step-migration where a huge number of immigrants ultimately settle city from the surrounding sub-urban and fringe areas.

The drop in the birth rate among the dwellers in the megacities is attributed to expensive lifestyle in these superurban areas where land rent, accommodation as well as expenses on food is tremendously high. The percentage of child population in the $0-6$ years age group in 2001 was 13.23 in the megacity of Ahmedabad which has recorded a decline to 11.68 per cent in 2011. In case of Bengaluru, the percentage decline was -0.88 in the decade of 2001-2011. The megacity of Chennai, situated in the southern major State of Tamil Nadu, has been the only megacity which has registered an increase by 0.1 per cent. In Delhi, the percentage drop has been -2.57 during the same decade which has been highest as well. Among the two megacities, situated in the western major State of Maharashtra, Pune has 


\section{International Journal of Science and Research (IJSR) \\ ISSN (Online): 2319-7064}

Index Copernicus Value (2013): 6.14 | Impact Factor (2015): 6.391

recorded a sharp decline of -2.13 per cent in comparison to that to Mumbai in the same decade under discussion. In Kolkata, the drop in the fertility rate has invariably affected the percentage of child population to total population during the decade 2001-2011. The city has recorded a drop of 0.98 per cent in the proportion of children. The expensive lifestyle in these cities, coupled with widespread use of family planning devices, have somewhat contributed in bringing down the birth rate.

\subsection{General and Child Sex Ratio}

Among the eight megacities of India, the highest general sex ratio was recorded in Chennai in 2001 (957) as well as in 2011 (989). In fact the general sex ratio has improved in the city substantially over the decade. In Delhi, the general sex ratio has increased from a miserable figure of 821 in 2001 to 868 in 2011.

In case of Mumbai, the general sex ratio has improved from 777 in 2001 to 832 in 2011. The megacity of Kolkata located within the eastern major State of West Bengal had a low general sex ratio of 829 in 2001 which has improved substantially to 908 in 2011 [Fig.1].

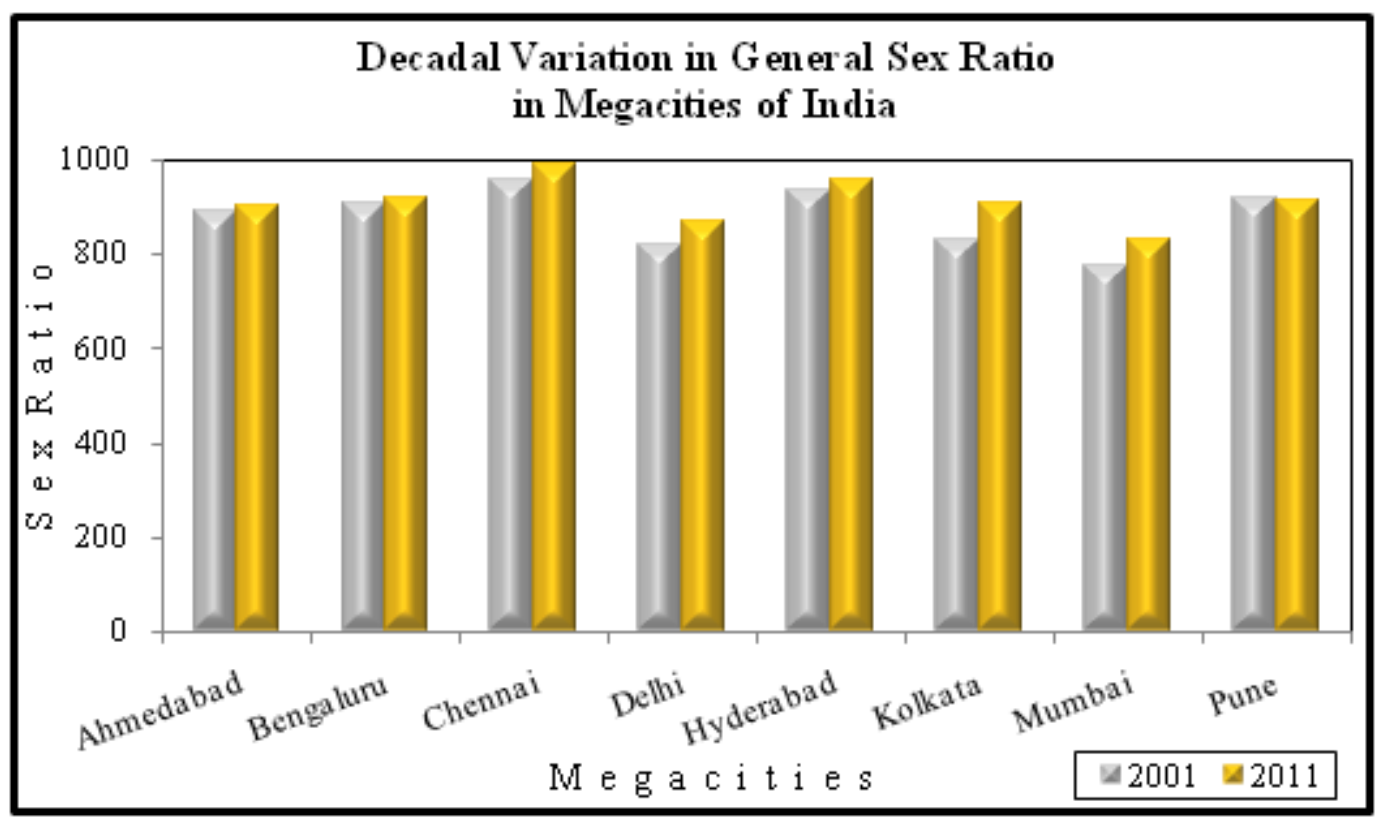

Data source: Census of India

Hyderabad in Andhra Pradesh has registered a massive decline in child sex ratio followed by Pune in Maharashtra. Kolkata (West Bengal) has somewhat hold a place of glory with an increase in child sex ratio from 927 in 2001 to 933 in 2011. Delhi has also recorded a marginal increase in child sex ratio from 867 in 2001 to 871 in 2011. Bengaluru recording a marginal improvement in child sex ratio is the megacity in the South with a positive growth (943 in 2001 and 944 in 2011) in comparison to other two megacities of Chennai and Hyderabad.

The sex ratio at birth has been highest in Bengaluru followed by that in Pune. Bengaluru is in fact noted for least prevalence of gender discrimination owing to high literacy rate both among the male and female population along with high work participation rate of both the men and women. The reasons attributed to low child sex ratio coupled with its further decline in the megacities is the existence of inhuman practices of sex-selective abortion which tend to affect and alter the sex ratio at birth and incidences of female infanticide.

\subsection{Maternal Health Aspects}

The eight megacities have also improved the maternal health related condition which has directly exerted an influence on dropping down the number of maternal deaths along with improvement in neonatal health.

There is dominance of institutional deliveries in these megacities though 4.8 per cent of the deliveries are still conducted in households of Pune followed by 4.1 per cent in Bengaluru in 2012-2013. In case of Kolkata, 1.7 per cent of the deliveries were conducted in the households while the lowest percentage was recorded in Chennai (0.7\%) [Fig.2]. In Chennai, since the percentage of domiciliary deliveries were lowest, the percentage of live births was highest (99.7\%) followed by that of Hyderabad (96.4\%) [Ministry of Health and Family Welfare, 2014]

After delivery, a woman needs regular health monitoring and check-ups to restore her physiological condition and treat incidences of post-pregnancy complications. In Bengaluru, 94.50 per cent of the lactating mothers have received post-natal treatment within 48 years of delivery while in Chennai the percentage has been 81.60 in 20122013. In Hyderabad, 83.0 per cent of the new mothers have undergone post-partum check up while in the western megacities of Mumbai and Pune such percentage figures were 88.40 and 88.80 respectively in the same financial year. In Kolkata such percentage has been 74.10 in 2012 2013. 
International Journal of Science and Research (IJSR)

ISSN (Online): 2319-7064

Index Copernicus Value (2013): 6.14 | Impact Factor (2015): 6.391

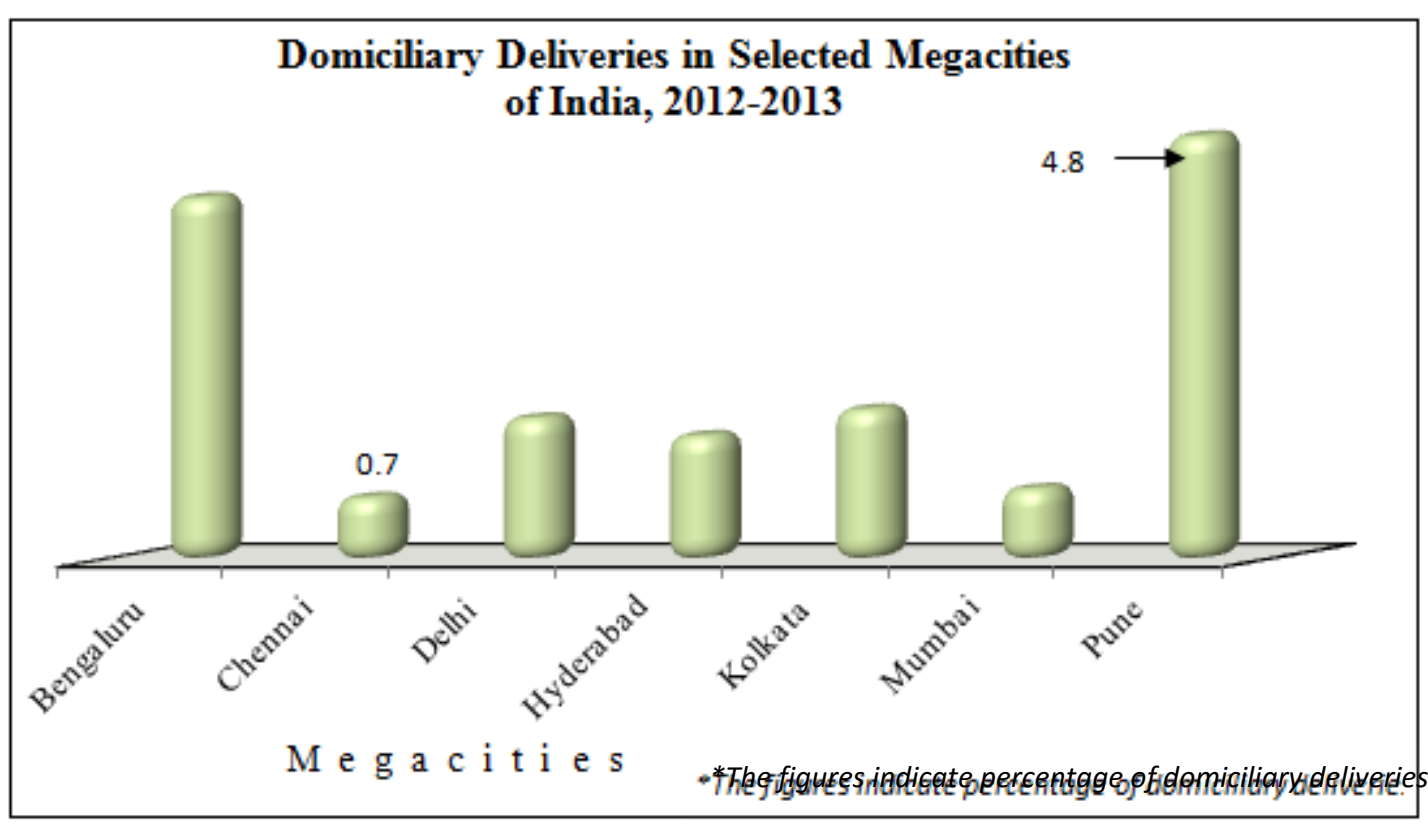

Figure 2

Data source: Ministry of Health and Family Welfare, Govt. of India

Mother's milk is vital for the neonates since it provides all the vital nutrients and protects the baby from various diseases after birth. In India, only 44 per cent of the neonates are breast-fed within one hour of birth [The Times of India, September, 2015]. The practice of breast-feeding of infants within first six months of life has been appreciably high in Kolkata followed by that in Pune [Fig.3].

\subsection{Issues Related to Survival in Childhood}

In 2012-2013, the infant mortality rate (IMR) per 1,000 live births in Delhi was 25. The rate was, however, 48.38 in Kolkata in 2013-2014. The Under-five mortality rate (U5MR) per 1,000 live births in 2012-2013 was 5.7 in Delhi while it was 50.76 in Kolkata in 2013-2014. The perinatal as well as the neonatal mortality rate in the megacities have always been high since the number of deaths here includes both the local as well as the referred patients from the surrounding districts, neighboring States and countries.

30.50 per cent of the children in Bengaluru were found to be affected with anemia followed by 25.90 per cent in Pune in 2012-2013. However, the percentage has been appreciably low in Chennai $(3.7 \%)$ followed by that in Kolkata $(7.1 \%)$ indicating the good performance of the programmes relating to the elimination of anaemia though the prevalence of such disorder is quite acute among the slum and shanty dwelling women [Fig.4].

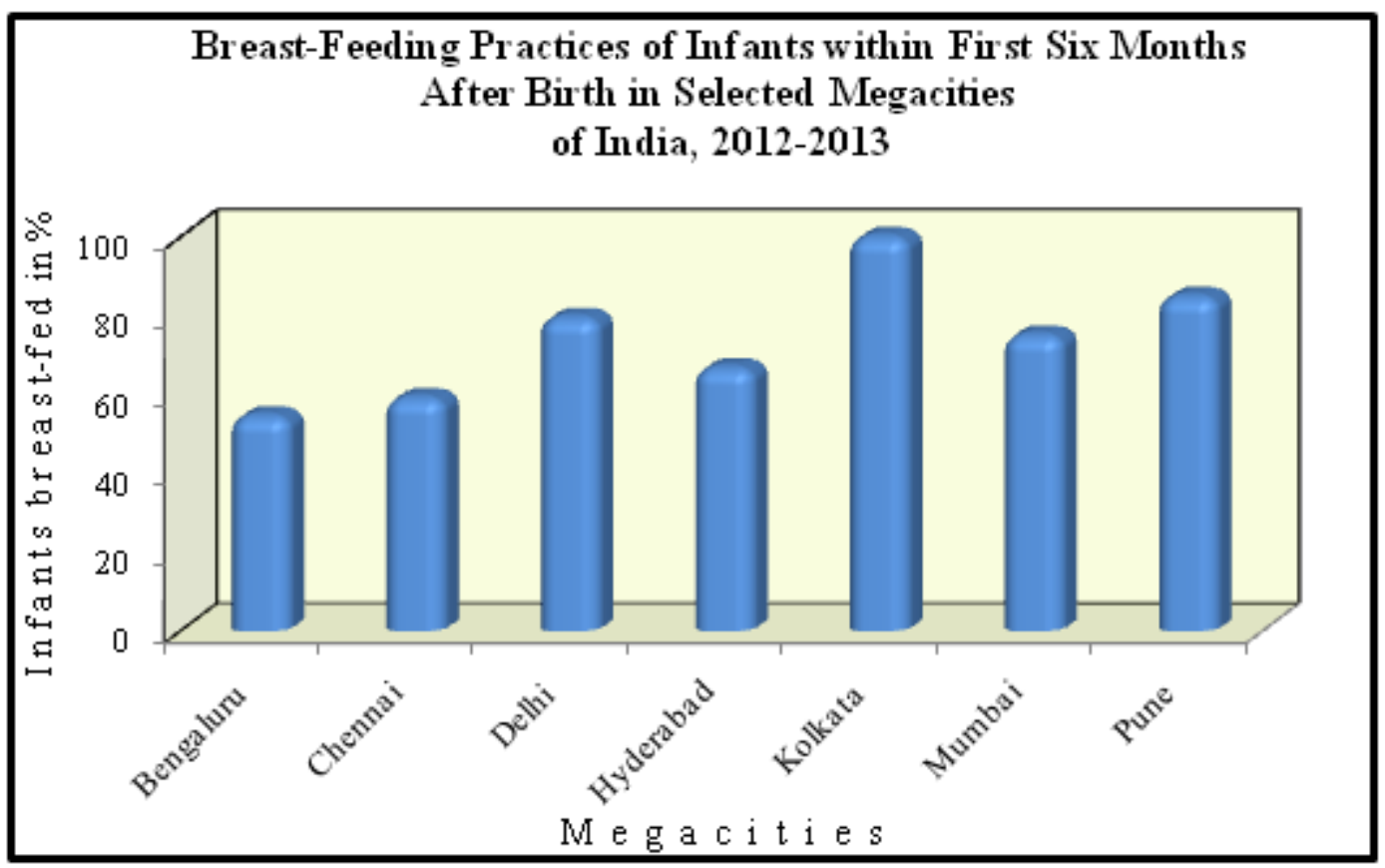

Figure 3

Data source: Government of India

Volume 5 Issue 6, June 2016 www.ijsr.net 


\section{International Journal of Science and Research (IJSR) \\ ISSN (Online): 2319-7064}

Index Copernicus Value (2013): 6.14 | Impact Factor (2015): 6.391

In Pune, out of 96.3 per cent of the neonates weighed at birth, 15.0 per cent were found to be underweight in 20122013. The percentage has been more or less similar in all the megacities. The high percentage of low birth-weight neonates especially among the pregnant women in slums and shanties is due to the absence of antenatal care coupled with adequate nutritious diet and rest during pregnancy. The children below six years of age are frequently affected by a number of air-borne, water-borne and vector-borne diseases. Among the infants the foremost water-borne major disease is neonatal jaundice.

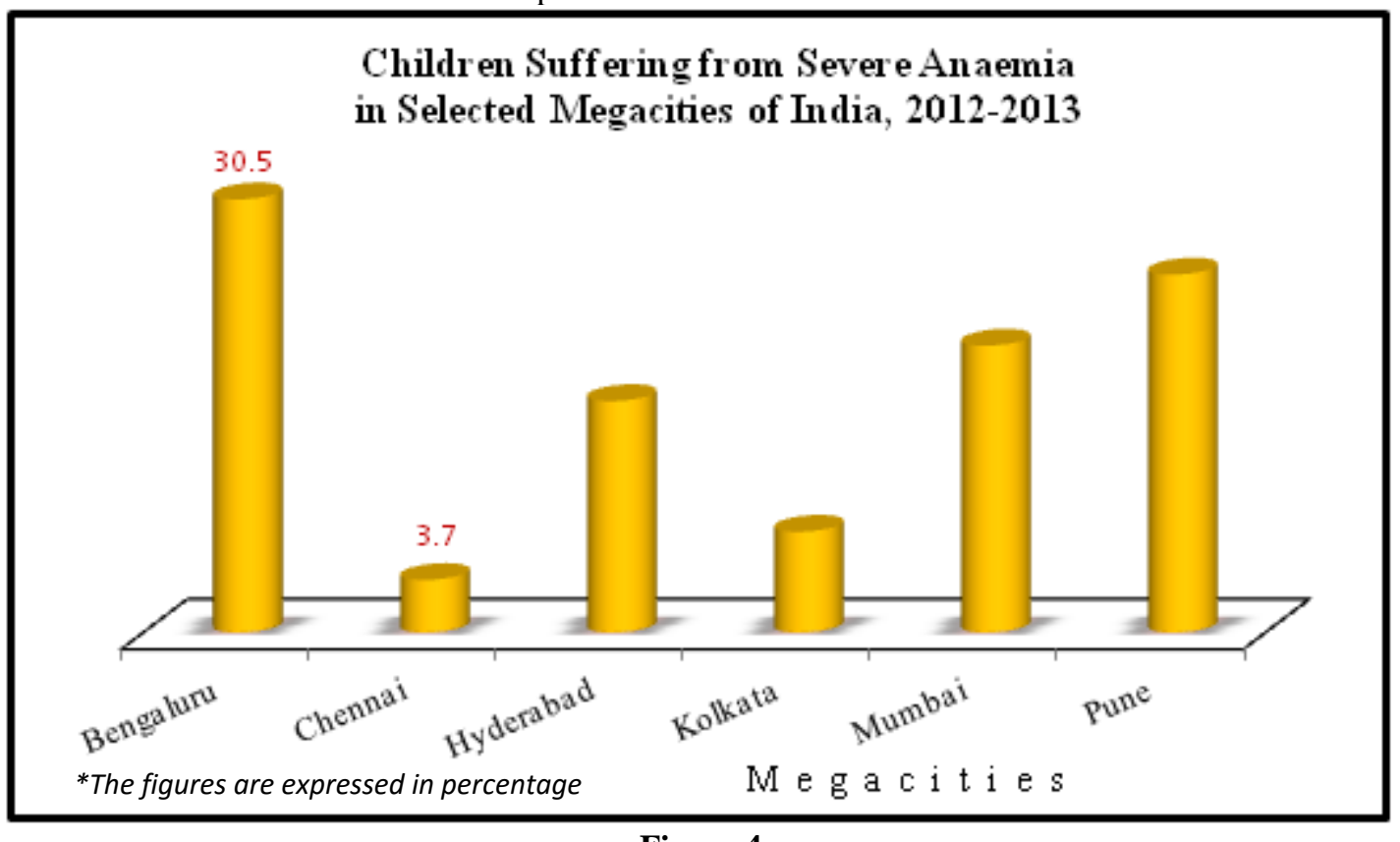

Figure 4

Data source: Ministry of Health and Family Welfare, Govt. of India

Among the children residing in the slums and shanties as well as the BPL group of population, the prevalence of neonatal jaundice is very high due to lack of awareness among the mothers regarding proper feeding practices and infantile care. The second most prevalent disease among children includes another water-borne disease i.e. diarrhoea and dehydration which involves passage of watery stools. Sometimes due to improper sterilization of the feeding bottles, inadequacy of cleanliness and hygiene maintained in the households or consuming food without washing hands contributes to the outbreak of typhoid and other related water-borne diseases.

The most common type of air-borne disease affecting child population of both the slums as well as the residents of the houses and apartments in the megacities is influenza. Acute Respiratory Infection (ARI) is another widespread air-borne disease with its prevalence recorded in 15.5 per cent of the children in Kolkata followed by 6.1 per cent in Bengaluru.

\section{Government Initiatives undertaken at State and Central Levels}

The Government of India has initiated several maternal and child welfare measures since the inception of the First Five Year Plan (1951-1956) in the form of National Health Programmes targeting both the mother and her child. These health related welfare programmes have been implemented by the State Governments from time to time with the initial funds provided by the Government of India. One of such welfare schemes is the Integrated Child Development Services (ICDS) Scheme launched by the Government of India in the year 1975 and subsequently implemented in every State. The target groups under ICDS Scheme include pregnant women, lactating mothers, children up to six years of age and the adolescent girls. A number of benefits are provided to the beneficiaries including free distribution of iron tablets to pregnant women, encouraging institutional child births, free treatment for mothers and children, providing food to children attending Anganwadi schools etc. Another significant maternal welfare programme that was implemented in 2005 was the Janani Suraksha Yojana (JSY) which aimed at improvement of institutional deliveries by providing monetary incentives to pregnant women. In 20122013, 11.3 per cent of the institutional births and 12.5 per cent of the domiciliary births were conducted under JSY in Pune. The domiciliary deliveries conducted under JSY are carried out by trained health personnel. As a result of which the chance of neonatal deaths has reduced.

The implementation of the Universal Immunization Programme (UIP) has been fantastic in the megacities. The programme was launched in 1985-1986 to cover child population under the scheme of vaccination against six dreadful diseases namely poliomyelitis, measles, diphtheria, pertussis (whooping cough), tetanus and tuberculosis by 1990. Children below six years of age are administered BCG vaccination to avert tuberculosis while DPT vaccination is given to eliminate diphtheria-pertussis-tetanus diseases among the child population. This programme has been performing satisfactorily since its inception.

At State level, an innovative health financing scheme was introduced in Gujarat in 2005-2006 under the name of Chiranjeevi Yojana to provide emergency obstetric care and emergency transport services for women in the BPL category. A number of operational Maata Vikas Kendra 


\section{International Journal of Science and Research (IJSR) \\ ISSN (Online): 2319-7064}

Index Copernicus Value (2013): 6.14 | Impact Factor (2015): 6.391

could be seen in the State of Maharashtra to provide comprehensive care to pregnant women in the form of antenatal care. In West Bengal, the Sishu Sathi Scheme was introduced in the year 2013 providing a major boost to child care.

\section{Findings of the Study}

This research endeavor which was initiated to find out the status of child health in the eight megacities of India has thrown light on some interesting facets. The eight megacities of India are in reality the urban magnets which serve as growth poles as well. The 'World City' of Mumbai (erstwhile Bombay) which has emerged as the 'Commercial City' of India has the largest proportion of slum population in comparison to other megacities in the country. Dharavi in Mumbai is the biggest slum in Asia. The slum population has not only increased in Mumbai but in every megacity of the country this unwanted growth of slum and shanty population has posed a threat to the city's general health concerned.

This population group is in fact deprived of the socioeconomic resources and is characterized with poverty and low standard of living. They usually do not have enough financial strength to avail good medical facilities. The unrestrained growth of population in the megacities is due to inter-urban migration. In megacities like Kolkata and Mumbai, urban to sub-urban migration is also conspicuous. Here the middle-income group of city dwellers is compelled to shift their base from the city core to the peripheral areas owing to high land rent and cost of living on one hand and transition from joint to nuclear family on the other. This perhaps explains the formation of city outgrowths in the form of Greater Kolkata and Greater Mumbai.

The social infrastructure especially health has been of much importance when discussing about the megacities. The general sex ratio has been outstanding in the megacity of Chennai followed by Hyderabad and Bengaluru. It is noteworthy to mention here that all the three megacities belong to the southern major States of Tamil Nadu, Andhra Pradesh and Karnataka. The megacity of Kolkata has recorded a glorious increase in child sex ratio followed by Delhi and Bengaluru. In fact, the sex ratio at birth has been highest in the southern megacity of Bengaluru followed by the western megacity of Pune. Bengaluru has exhibited least existence of gender discrimination with pride owing to high literacy rate especially among women. The child sex ratio in these cities of first order remains generally low due to the prevalence of malpractices inclusive of female foeticide and female infanticide.

The situation of maternal and child health is in a sound condition in the megacities of Chennai and Hyderabad. In Bengaluru, the proportion of children suffering from anaemia is acute which somewhat reflects the limited acceptance of Government run health related welfare programmes among the so-called affluent and educated class. The proportion of children with severe anaemia is, however, low in the southern megacity of Chennai and the eastern megacity of Kolkata. The practice of breast-feeding has been appreciably high among the mothers of Kolkata in comparison to the new mothers of Bengaluru and Chennai. This is mainly due to the highly urbanized and hectic lifestyle among the women in the southern megacities accompanied with diminishing realization of motherly affection.

The implementation of the Universal Immunization Programme (UIP) has been satisfactory. This Programme was launched in the country with an aim to make the children free from the clutches of dreadful and fatal diseases including diphtheria, whooping cough, measles and tetanus. The performance of Intensified Pulse Polio Immunization Programme (IPPI) has been of worth mentioning in combating and eradicating the paralytic disease of poliomyelitis. This disease is rarely found among the child population of the megacities. Another maternal and child related welfare scheme was the Integrated Child Development Services (ICDS) Scheme which has been rigorously implemented in these megacities though the success of the programme is somewhat restricted to the lowincome and below poverty line group of population. The performance of National Urban Health Mission and Janani Suraksha Yojana is also limited to the aforementioned income group of population. In fact, a little proportion of the high-income and upper-middle income groups of population avail the opportunity of Government run health care facilities. The Government run medical colleges and hospitals are mainly visited by the lower-middle income group of population along with the low-income and below poverty line groups of population. These public medical institutions are also flooded with patients from surrounding rural and sub-urban areas. The exception in this regard is Chennai where patients from other megacities especially from Kolkata visit the Government run hospitals and health care centres to avail modern treatment. Even the acute and critical ailments and incidences of emergencies are said to be dealt with perfection in the Chennai hospitals.

\section{Conclusion}

The eight megacities of India are in fact the 'growth points' from where the waves of development spread in every sphere. The megacities with their rich history of culture and tradition coupled with the rapid rate of urbanization have served as growth magnets with efficient administration and socio-economic as well as cultural norms. Their catchment areas and outgrowths are served by the city proper by providing both the social as well as economic infrastructure. The population from surrounding rural and peripheral areas as well as from tinsel towns and cities of other States visit these megacities with a dream to prosper in life. The social infrastructure in these megacities deserves special mention with the existence of multi-specialty hospitals run under both the public and private organizations. These hospitals and nursing homes are equipped with modern health care facilities and have the capacity to deal with emergency cases at the same time. These medical institutions have separate and distinct departments for the treatment and care of the pregnant woman and her baby. In fact, the critical cases from the remote rural areas as well as from the surrounding and distant urban units are referred to the hospitals in the megacities for better treatment. The existence of improved medical facilities is both a blessing and a curse for these 


\section{International Journal of Science and Research (IJSR) \\ ISSN (Online): 2319-7064}

Index Copernicus Value (2013): 6.14 | Impact Factor (2015): 6.391

megacities. Often the crises for beds and emergency blood strike these hospitals leading to untimely deaths of patients. The situation of infant and child mortality is critical in the megacity of Kolkata despite the existence of sick neonatal care units mainly due to lack of adequate infrastructure to meet the requirements of huge immigrating patients from surrounding districts and States. The scenario is somewhat different in Chennai which has now emerged as a reliable destination for medical tourists from India and neighboring countries. Despite several discrepancies and lacunae in health care facilities, the significance of the megacities in providing maternal and child health related services must be mentioned with pride. These cities in fact serve as 'feather to the cap' of glory of the country.

\section{References}

[1] Government of India (2011). Primary Census Abstract Series-I, Registrar General and Census Commissioner of India, New Delhi

[2] Government of India (2012). Family Welfare Statistics in India 2011, Ministry of Health and Family Welfare, New Delhi

[3] Government of India and International Institute of Population Sciences (2014): District Level Household and Facility Survey 2012-13, Ministry of Health and Family Welfare, New Delhi

[4] The Times of India (2015). Only 44 per cent Breast-fed in the First hour of Birth in India: Even Bengal, Africa and Lanka Rank Better, September 2, 2015, Kolkata

[5] Whaba, J. (1996). Urbanization and Migration in the Third World, Economic Review, Vol.14, No.2, United Kingdom

\section{Author Profile}

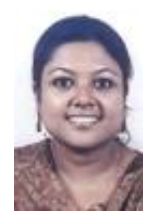

Ms. Anandita Dawn has completed her Bachelor's and Master's degree in Geography under the reputed and century old University of Calcutta, Kolkata, West Bengal. She has pursued her Ph.D. level research as the UGC-Senior Research Fellow under the same university. Her main thrust areas of study include human geography emphasizing on social studies of gender as well as reproductive health. She has a number of research papers published in various national and international peer-reviewed journals focusing on various aspects of maternal and child health.

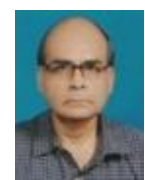

Dr. Ranjan Basu obtained his post-graduate degree and doctoral degree from the University of Calcutta. He started his professional career in 1976 as a researcher in the then National Atlas Organization, Government of India. He opted for teaching profession and joined Darjeeling Government College in 1979 wherefrom he shifted to the University of Burdwan in 1980 and subsequently to the University of Calcutta in 2001. His areas of interest include Pedology, Biogeography, Social Geography and Environmental Issues in Geography. He is a Professor of Geography since 1998. He has more than 50 major papers published in edited books and various national and international journals apart from three edited books and two edited monographs to his credit. At present he is the Co-ordinator of the UGC sponsored 'Departmental Research Support' Programme in the University of Calcutta. He has successfully supervised about sixteen Ph.D. theses. He was the editor of the journal
'Geographical Review of India' (ISSN No. 0375-6386) from 2011 to 2014 . 